\title{
Genotypic and Phenotypic Characteristics of Hereditary Colorectal Cancer
}

\author{
Jin Cheon Kim ${ }^{1,2}$, Walter F. Bodmer ${ }^{3}$ \\ ${ }^{1}$ Department of Surgery, University of Ulsan College of Medicine and Asan Medical Center, Seoul; ${ }^{2}$ Laboratory of Cancer Biology and \\ Genetics, Asan Institute for Life Sciences, Asan Medical Center, Seoul, Korea; ${ }^{3}$ Cancer and Immunogenetics Laboratory, Weatherall Institute \\ of Molecular Medicine, John Radcliffe Hospital, University of Oxford, Oxford, United Kingdom
}

The genomic causes and clinical manifestations of hereditary colorectal cancer (HCRC) might be stratified into 2 groups, namely, familial (FCRC) and a limited sense of HCRC, respectively. Otherwise, FCRC is canonically classified into 2 major categories; Lynch syndrome (LS) or associated spectra and inherited polyposis syndrome. By contrast, despite an increasing body of genotypic and phenotypic traits, some FCRC cannot be clearly differentiated as definitively single type, and the situation has become more complex as additional causative genes have been discovered. This review provides an overview of HCRC, including 6 LS or associated spectra and 8 inherited polyposis syndromes, according to molecular pathogenesis. Variants and newly-identified FCRC are particularly emphasized, including MUTYH (or MYH)-associated polyposis, Muir-Torre syndrome, constitutional mismatch repair deficiency, EPCAM-associated LS, polymerase proofreading-associated polyposis, RNF43- or NTHL1-associated serrated polyposis syndrome, PTEN hamartoma tumor syndrome, and hereditary mixed polyposis syndrome. We also comment on the clinical utility of multigene panel tests, focusing on comprehensive cancer panels that include HCRC. Finally, HCRC surveillance strategies are recommended, based on revised or notable concepts underpinned by competent validation and clinical implications, and favoring major guidelines. As hereditary syndromes are mainly attributable to genomic constitutions of distinctive ancestral groups, an integrative national HCRC registry and guideline is an urgent priority.

Keywords: Hereditary neoplastic syndrome; Colorectal neoplasms; Lynch syndrome; Adenomatous polyposis coli; Interstitnal polyposis

\section{INTRODUCTION}

Malignant neoplasms are multifaceted, comprising various clones, and comprehensive understanding of carcinogenesis requires detailed information, not confined to a specific disease stage. The ongoing process involved in carcinogenesis is conveyed by the word "neoplasm" meaning "forever fresh." Tumor formation essentially constitutes a sequential stepwise accumulation of alterations, as

Received: Oct 5, 2021 - Accepted: Oct 21, 2021

Correspondence to: Jin Cheon Kim, M.D., Ph.D.

Department of Surgery, University of Ulsan College of Medicine,

88 Olympic-ro 43-gil, Songpa-gu, Seoul 05505, Korea

Tel: +82-2-3010-3489, Fax: +82-2-474-9027

E-mail: jckim@amc.seoul.kr

ORCID: https://orcid.org/0000-0003-4823-8619

(C) 2021 The Korean Society of Coloproctology

This is an open-access article distributed under the terms of the Creative Commons Attribution NonCommercial License (https://creativecommons.org/licenses/by-nc/4.0) which permits unrestricted noncommercial use, distribution, and reproduction in any medium, provided the original work is properly cited. evidenced by serial histopathological and molecular changes. Mutation analysis of 189 genes in 13 samples of primary colorectal cancer (CRC) and matched metastases revealed an overall concordance rate of $78 \%$, while exclusion of rare mutations (potential passenger mutations) raised the rate to $90 \%$ [1]. By contrast, genomic profiling of 349 individual glands from 15 colorectal tumors revealed the absence of selective sweeps, and instead detected a uniformly high level of intratumoral heterogeneity and subclonal mixture in distant regions, supporting the so-called "Big Bang" model of tumor development [2]. Accordingly, the majority of private mutations occur early after transition to the advanced tumor stage, rather than as a result of the subsequent selection of $d e$ novo clones. The 2 most prevalent routes of colorectal carcinogenesis were determined by study of Lynch syndrome (LS) and familial adenomatous polyposis (FAP), as representative familial CRC (FCRC). Hereditary CRC (HCRC) occur via a number of oncogenic pathways, which involve various relevant genes and their interactions. Here, we described molecular pathogenesis and ge- 
Table 1. Causative genes and clinical manifestations of Lynch syndrome and associated spectra

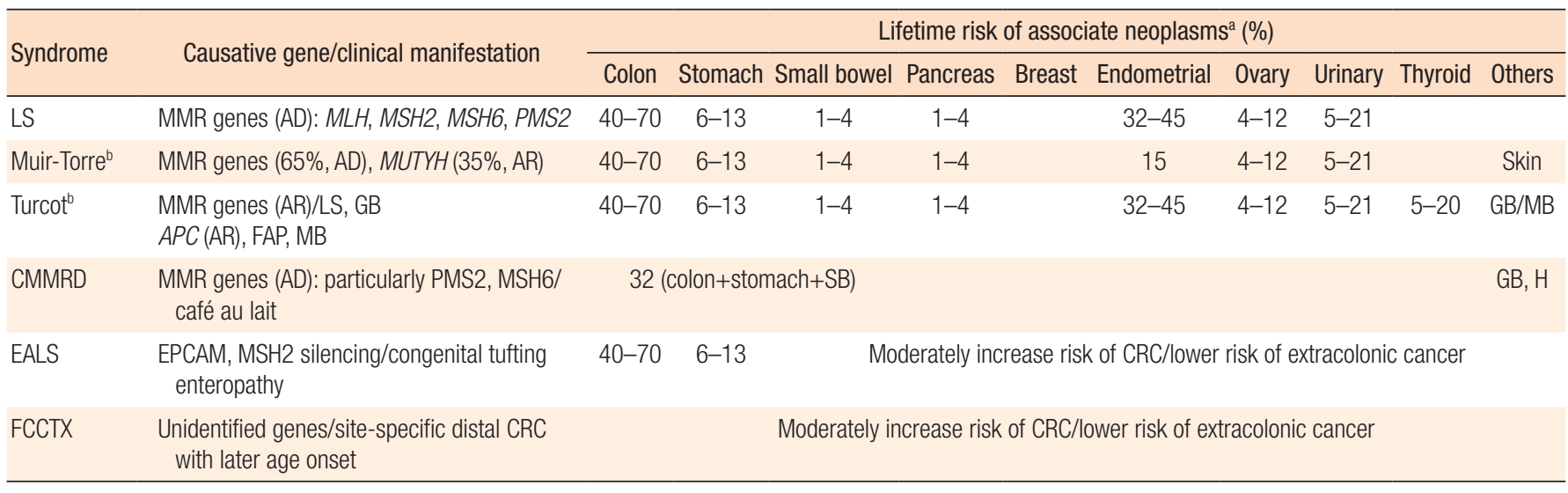

LS, Lynch syndrome; MMR, mismatch repair genes; AD, autosomal dominant; AR, autosomal recessive; GB, glioblastoma; FAP, familial adenomatous polyposis; MB, medulloblastoma; CMMRD, constitutional MMR deficiency; SB, small bowel; $\mathrm{H}$, hematological malignancy; EALS, EPCAM-associated LS; CRC, colorectal cancer; FCCTX, famili-al colorectal cancer type $X$.

aLifetime syndrome risks mostly based on the American College of Gastroenterology Guideline of Hereditary Gastrointestinal Cancer Syndromes (2015; https://gi.org/

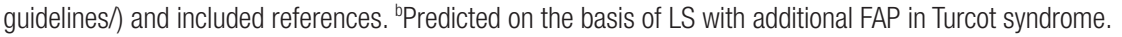

nomic alterations in HCRC and their clinical application, including genetic testing, and surveillance.

\section{A SPECTRUM OF HEREDITARY COLORECTAL CANCER}

CRC was among the first solid tumors to be molecularly characterized, and several genes and pathways are implicated in CRC tumor initiation and growth [3]. Bodmer et al. [4] explored gene alterations causative of FAP localized to chromosome 5q21-q22 as determined by linkage analysis of DNA markers from 124 subjects in 13 different FAP families, with further analysis showing that this locus was located at chromosome 5q22.2. The stepwise "adenoma-carcinoma" continuum is a principal CRC progression model first proposed by Fearon and Vogelstein [5] as a process that initiates with the formation of benign tumors (adenomas and sessile serrated polyps), followed by sequential steps of progression to more histologically invasive cancer. Molecular alterations underlying CRC progression are generally acquired early in the carcinogenic process, and there is substantial inter-connectivity among genomic drivers, transcriptomic subtypes, and immune signatures $[3,6]$.

Approximately 25\% of all CRCs have been found to be FCRC (5\%) and a limited sense of HCRC (20\%), respectively (HCRC in this review includes both FCRC and a limited sense of HCRC) [7, 8]. The former category includes a variety of genetically verified syndromes with high penetrance of CRC, whereas the latter can include any familial occurrences of CRC due to mostly multigenic variants, each with low-level effects on the basis of an analysis of polygenic risk scores [9]. FCRC is canonically stratified into 2 categories; LS or LS-associated spectra and inherited polyposis syndrome. The former includes classical LS, Muir-Torre syndrome,
Turcot syndrome, constitutional mismatch repair deficiency (CMMRD) syndrome, EPCAM-associated LS, and transiently called FCRC type X (FCCTX) (Table 1). The latter comprises a broad spectrum associated with multiple polyposis, including FAP, MUTYH-associated polyposis (MAP), polymerase proofreading-associated polyposis (PPAP), serrated polyposis syndrome (SPS), Peutz-Jeghers syndrome (PJS), juvenile polyposis syndrome (JPS), PTEN hamartoma tumor syndrome (PHTS), and hereditary mixed polyposis syndrome (HMPS) (Table 2).

\section{LYNCH SYNDROME AND ASSOCIATED SPECTRA}

\section{Lynch syndrome}

LS, previously known as a conventional hereditary nonpolyposis colorectal cancer, carries estimated lifetime CRC risk rates of $70 \%$ and $40 \%$ for males and females, respectively (range, 22\%-75\%) [10]. The term "nonpolyposis" is a misnomer, as almost all colorectal polyps can be LS precursor lesions, which typically present with villous growth and high-grade dysplasia [11]. Endometrial adenocarcinoma is the most common extracolonic cancer in LS, with a lifetime risk of $32 \%$ to $45 \%$, followed by ovarian, small bowel, gastric, urinary tract, pancreas, and brain cancers. Almost all LS CRCs exhibit a defective DNA mismatch repair (MMR) phenotype, and can be distinguished from sporadic high microsatellite instability (MSI) CRCs in that LS tumors lack somatic BRAF mutations and $M L H 1$ promoter hypermethylation, which are hallmarks of the serrated route to CRC [10]. Among the $>3,000$ unique germline sequence variants in the $4 \mathrm{LS}$-associated MMR genes deposited in the InSiGHT locus-specific database, 40\%, 34\%, $18 \%$, and $8 \%$ are alterations of $M L H 1, M S H 2, M S H 6$, and PMS2, respectively [12]. Although total lifetime risk for CRC in MSH6 
Table 2. Causative genes and clinical manifestations of inherited polyposis syndrome

\begin{tabular}{|c|c|c|c|c|c|c|c|c|c|c|c|c|}
\hline \multirow{2}{*}{ Syndrome } & \multirow{2}{*}{ Causative gene } & \multirow{2}{*}{ Clinical manifestations } & \multicolumn{10}{|c|}{ Lifetime syndrome risk of associate neoplasms ${ }^{a}(\%)$} \\
\hline & & & Colon & Stomach & Small bowel & Pancreas & Breast & Endometrial & Ovary & Urinary & Thyroid & Others \\
\hline FAP & $A P C(A D)$ & $\begin{array}{l}\text { Benign soft tissue tumor, } \\
\text { CHRPE }\end{array}$ & $\begin{array}{c}90 \\
\left(69^{b}\right)\end{array}$ & $2-5$ & $5-20$ & $2-5$ & & & & & $5-20$ & $\begin{array}{l}\text { Desmoid, } \\
\text { MB }\end{array}$ \\
\hline MAP & MUTYH (AD) & $\begin{array}{l}\text { CRC-proximal colon, mucin, } \\
\text { LC infiltration }\end{array}$ & $43-63$ & \multicolumn{9}{|c|}{ Less common than those in FAP, otherwise similar spectrum to LS } \\
\hline PPAP & $\begin{array}{l}\text { POLE, POLD1 } \\
\text { (AD) }\end{array}$ & LS-like phenotype in a minority & 70 & & 9.5 & & & 12 & $\mathbb{R}$ & & & \\
\hline $\begin{array}{l}\text { Sessile } \\
\text { polyposis }\end{array}$ & RNF43 (AD) & $\begin{array}{l}\geq 5,>\text { rectum }(\geq 2, \geq 10 \mathrm{~mm}) \\
\geq 20(\geq 5,>\text { rectum })\end{array}$ & 20 & \multicolumn{9}{|c|}{ Undetermined } \\
\hline $\begin{array}{l}\text { Peutz- } \\
\text { Jeghers }\end{array}$ & STK11 (AD) & $\begin{array}{l}\text { Mucocutaneous pigmented } \\
\text { macules }\end{array}$ & 40 & $5-20$ & $2-5$ & 5-20 & 50 & 10 & 20 & & & \\
\hline $\mathrm{JP}$ & $\begin{array}{l}\text { SMAD4, } \\
\text { BMPR1A (AD) }\end{array}$ & $\begin{array}{l}\geq 5 \text {, extrabowel JP, family } \\
\text { history }\end{array}$ & $20-40$ & 5-20 & & & & & & & & \\
\hline
\end{tabular}

FAP, familial adenomatous polyposis; AD, autosomal dominant; CHRPE, congenital hypertrophy of retinal pigment epithelium; MB, medulloblastoma; MAP, MUTYH-associated polyposis; CRC, colorectal cancer; LC, lymphocyte; LS, Lynch syndrome; PPAP, polymerase-proofreading-associated polyposis; IR, increased rate; JP, Juvenile polyposis; PHTS, PTEN hamartoma tumor syndrome; BRRS, Bannayan-Riley-Ruvalcaba syndrome; CS, Cowden syndrome; GS, Gorlin syndrome; PS, Proteus-like syndromes; Gl, gastrointestinal; HMPS, hereditary mixed polyposis.

aLifetime syndrome risks mostly based on the American College of Gastroenterology Guideline of Hereditary Gastrointestinal Cancer Syndromes (2015; https://gi.org/ guidelines/) and included refer-ences; PPAP based on the National Study of Colorectal Cancer Genetics (2013), UK; PHTS based on the International Cowden Consortium

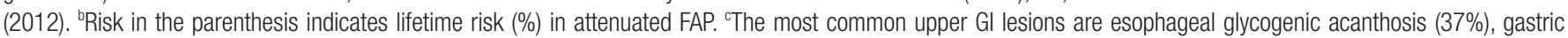
hamartomatous polyps (47\%), and duodenal hamartomatous polyps (20\%).

mutation carriers is similar to that associated with $\mathrm{MSH} 2$ and $M L H 1$, tumors tend to occur in the elderly in these patients, similar to sporadic CRCs $[13,14]$.

The MSH2/MSH6 protein complex, MutS, recognizes single-nucleotide base-pair mismatches, while a second heterodimer complex, comprising MLH1 and PMS2, MutL, binds to MutS and triggers "long-patch excision" of newly-synthesized DNA. Loss of DNA MMR activity results in the rapid accumulation of mutations, generating a hypermutated genomic environment thought to accelerate carcinogenesis [10]. LS-associated tumors exhibit accelerated transition from adenoma to carcinoma, with frequent reports of "interval" cancers developing within 1- to 2-year intervals after colonoscopy $[15,16]$; however, LS-related CRCs are less prone to nodal and distant metastatic spread compared with sporadic CRC, despite their apparently high-risk histologic features [7].

\section{Muir-Torre syndrome}

The hallmark features of Muir-Torre syndrome are sebaceous neoplasms of the skin and colonic carcinoma, which are the most common visceral malignancies [17]. Additionally, all LS-associated extracolonic tumors can also occur in Muir-Torre syndrome, as well as hematologic malignancies and lung cancer. Some autosomal recessive cases of Muir-Torre syndrome have been described without MSI and are caused by defects in base excision repair (BER) genes, such as MUTYH [18]; such cases account for approximately $35 \%$ of Muir-Torre syndrome, and are referred to as Muir-Torre syndrome II. Three histologic variants of dermatologic lesions occur in Muir-Torre syndrome; solid, cystic, and keratoacanthomalike. Lesions can be sebaceous adenomas, sebaceous epitheliomas, sebaceous carcinomas, cystic sebaceous tumors, basal cell carcinomas with sebaceous differentiation, or keratoacanthomas.

\section{Turcot syndrome}

Turcot syndrome is LS associated with primary brain tumors. Notably, either LS or FAP can co-segregate with Turcot syndrome, and are referred to as Turcot syndrome 1 and 2, respectively [19]. Turcot syndrome is mostly inherited by autosomal recessive transmission of biallelic MMR and APC mutations, and rarely as an autosomal dominant condition, with pleiotropic effects and variable expressivity. Glioblastoma may be caused by MMR gene mutations, specifically in $M L H 1$, whereas medulloblastomas are associated with mutations of APC [20]. Patients with Turcot syndrome 1 present with hematologic malignancies, café au lait spots, and glioma, particularly glioblastoma multiforme, while those with Turcot syndrome 2 who express the colonic polyposis phenotype tend to manifest the disease after 17 years of age (later than classical FAP), and those who do not express the colonic phenotype develop cerebellar medulloblastoma by 10 years of age [21]. FAP 
traits may also be accompanied by congenital hypertrophy of retinal pigment epithelium (CHRPE), subcutaneous or soft tissue benign tumors, and more critical duodenal neoplasms. Paraf et al. [21] attempted to reclassify Turcot syndrome into brain-tumor polyposis syndrome 1 and 2, referring to patients without and with FAP syndrome, respectively; however, patients with brain-tumor polyposis syndrome 2 may develop polyposis later, or may simply not survive long enough for it to emerge.

\section{Constitutional mismatch repair deficiency}

CMMRD is a highly-penetrant cancer predisposition syndrome caused by alterations of biallelic MMR genes and can be effectively detected using an in vitro G-T repair assay to assess MSH2-MSH6 and MLH1-PMS2 activity [22]. In contrast to the relatively low prevalence of tumors in the first 2 decades of life in patients with LS, individuals harboring homozygous or biallelic MMR gene mutations exhibit a distinct childhood cancer predisposition syndrome [23]. Similarly, the $\mathrm{MSH} 2$ mutations most commonly found in LS are less frequent or absent in CMMRD, while PMS2 and MSH6 mutations are more frequent in CMMRD. Specifically, $P M S 2$ is the gene most frequently mutated in CMMRD, with other MMR genes contributing up to $40 \%$ of cases [24].

All children with CMMRD have café au lait spots and most are from consanguineous families. Brain tumors are the most common cancers reported (48\%), followed by gastrointestinal (32\%), and hematological (15\%) malignancies. Fortunately, solid tumors are mostly low grade and resectable [23]. Tumor immunohistochemistry (IHC) assays provide $100 \%$ sensitivity and specificity for diagnosis of MMR deficiency, while MSI analysis is neither sensitive nor specific. Screening of normal tissue by IHC can also assist in genetic confirmation of CMMRD.

\section{EPCAM-associated Lunch syndrome}

The epithelial cell adhesion molecule gene, EPCAM, maps $17 \mathrm{~kb}$ upstream of $\mathrm{MSH} 2$ on the short arm of chromosome 2. EPCAM alteration was described in patients from Dutch and Chinese families with MSH2-deficient tumors carrying heterozygous germline deletions of the last exons of TACSTD1, a gene directly upstream of MSH2 encoding EPCAM [25]. Biallelic mutations in EPCAM cause congenital tufting enteropathy, a rare chronic diarrhea disorder, during infancy, whereas monoallelic deletions of the last exons of EPCAM cause LS in 1\% to 3\% of affected families [26]. Some studies have suggested that the frequency of EPCAM deletions causing LS is approximately $30 \%$ in patients with $\mathrm{MSH} 2$ mutation-negative tumors or around $20 \%$ in LS patients without MMR mutations [26]. EPCAM-associated LS carries a risk of CRC, similar to those of tumors with $M L H 1$ and $M S H 2$ mutations, whereas the cumulative risk of endometrial cancer in patients with $E P C A M$-associated LS is much lower [27, 28]. In other words, EPCAM-associated LS, epigenetic silencing of $M S H 2$ is tissue specific, leading to mosaic inactivation of MSH2, a high risk of CRC, and a low risk of endometrial cancer.

\section{Familial colorectal cancer type $\mathrm{X}$}

As many as $40 \%$ of CRCs fulfilling the LS clinical criteria are microsatellite stable (MSS) and transiently designated FCCTX. Patients with FCCTX have a moderately increased risk of CRC, with a low risk of extracolonic cancers [29]; the risk of CRC is lower than that in LS (relative risk, 0.5), but higher than that of the general population (standardized incidence ratio, 2.3) [30]. FCCTX appears to be associated with site-specific CRC (mainly distal) diagnosed at somewhat later ages compared with LS [12]. Causative genes for FCCTX remain poorly defined, although several candidates have been proposed via next generation sequencing (NGS)based assays, including $B C R, B L M, B R F 1$, CHEK2, FAN1, GABBR2, GALNT12, HABP4, KIF24, OGG1, RPS20, SEMA4A, and ZNF367. By contrast, some genes suggested to carry mutations causing FCCTX are known to cause inherited polyposis syndrome; for example, BMPR1A, MUTYH, and POLD1. One multigene panel (MGP) study of FCCTX found $>1$ high-penetrant non-LS gene mutation for every 5 LS mutations identified, suggesting that unexpected actionable genomic alterations may occur in patients with LS-like phenotypes [31]. To date, even for those few FCCTX families with plausible gene candidates, the true nature and penetrance of specific gene variants have yet to be proven.

\section{INHERITED POLYPOSIS SYNDROME}

\section{Familial adenomatous polyposis}

FAP occurs in 1 in 8,300 to 14,000 individuals, approximately onehalf of whom develop colorectal adenomas by the age of 16 years $[32,33]$. Patients with the classical FAP phenotype carry germline mutations in APC; and in $>90 \%$ of individuals, the lifetime risk for CRC exceeds $90 \%$ in the absence of proctocolectomy, along with increased risks of duodenal cancer, pancreatic cancer, medulloblastoma, and papillary thyroid cancer, as well as hepatoblastoma in children aged $<5$ years [10]. Desmoid tumors occur in $15 \%$ to $20 \%$ of patients during the second and third decades of life and are more frequent in patients with prior abdominal surgery and relevant family history [6]. Other benign lesions include osteomas (approximately 20\%), lipomas, epidermoid cysts, fibromas, dental abnormalities, and CHRPE, which is pathognomonic for FAP diagnosis.

Although FAP is associated with autosomal dominant inheritance, approximately $30 \%$ of affected individuals with germline APC mutations have no family history, and presumably, index patients have new mutations [34]. FAP can be classified according to the number of colonic adenomas detected as profuse $(\geq 1,000)$, classic (100-999), or attenuated $(<100)$. The attenuated FAP (AFAP) is conventionally indicated by adenomatous polyposis with $\leq 100$ colorectal adenomas and characterized by later onset polyposis and fewer extracolonic manifestations [35].

Multivariable analyses of 7,225 individuals, including 1,457 with classic polyposis and 3,253 with attenuated polyposis, showed that adenoma count is strongly associated with pathogenic APC muta- 
tions [36]. That study demonstrated prevalence rates of pathogenic APC and biallelic MUTYH mutations of $80 \%$ and $2 \%$ among individuals with $\geq 1,000$ or more adenomas, $56 \%$ and $7 \%$ in those with 100 to 999 adenomas, $10 \%$ and $7 \%$ among those with 20 to 99 adenomas, and 5\% and 4\% among those with 10 to 19 adenomas, respectively. Germline APC mutations around codon 1,300 (codons 1,286-1,513, designated the mutation cluster region [MCR]) are thought to result in severe colorectal polyposis [37]; patients tend to acquire somatic mutations as well as normal allelic loss, otherwise incurring truncating second hits. Somatic mutations in upper gastrointestinal polyps, including severe duodenal polyposis, occur between codons 1,400 and 1,580, retaining only one of the 20 -amino acid $\beta$-catenin-binding degradation repeats [38]. APC mutations at the $3^{\prime}$ and $5^{\prime}$ termini of the gene are generally associated with an attenuated phenotype, consisting of fewer polyps and later onset [10]. Further, pathogenic mutations in the promoter $1 \mathrm{~B}$ region ( $60 \mathrm{~kb}$ upstream of the transcription start site) were also reported in a pedigree from the Swedish polyposis registry without germline APC mutations [39].

\section{MUTYH-associated polyposis}

MAP tends to present later in life ( $>25$ years) compared with FAP and may predominantly develop in the proximal colon. MAP is characterized by mucin-rich histology and abundant lymphocyte infiltration, and patients have a better prognosis than those with sporadic CRCs [40]. Other common extracolonic features of FAP, such as gastric fundic gland polyps, are less commonly observed in the absence of desmoid tumor [32]. Additionally, some case reports have indicated that the spectrum of extraintestinal lesions in $M U T Y H$-associated disease differs greatly from that observed in FAP, and is rather more similar to that in LS, with significantly increased risk for ovarian, endometrial, bladder, and skin tumors [32].

MUTYH maps to the chromosome 1 locus, lp34, and contributes to the DNA BER system. The 2 most common MUTYH founder mutations, Y179C and G396D (previously referred to as Y165C and G382D), account for $70 \%$ to $80 \%$ of MAP cases among individuals of Northwestern European ancestry and are inherited by autosomal recessive transmission [10]. Approximately $1 / 3$ of persons with biallelic MUTYH mutations develop CRC in the absence of polyposis, suggesting incomplete penetrance [32]. Interestingly, $10 \%$ of Korean patients and their relatives with AFAP carried another heterozygous mutation in the BER gene, OGG1 (c.1-18G > T), with some heterozygous for the MUYTH A359V mutation, suggesting that there may be minor allele mutations in areas devoid of MUYTH founder mutations [41]. Another study identified heterozygous loss-of-function MSH3 mutations (e.g., c.1148delA, c.2319-1G > A, c.2760delC, and c.3001-2A > C) in a subgroup of patients with colorectal adenomatous polyposis [42].

\section{Polymerase-proofreading-associated polyposis}

Germline pathogenic variants affecting the exonuclease domain of the polymerases, POLE and POLD1, predispose to PPAP. According to a United Kingdom national study that screened 2,349 probands, the cumulative incidence rates of CRCs in heterozygotes for POLE and POLD1 variants are estimated as approximately $90 \%$ and $50 \%$, respectively [43]. Most patients have AFAPs, with few polyps; however, a minority of cases have an LS-like phenotype, with early-onset CRC and increased risks for endometrial and ovarian cancers [44]. Most POLE variant heterozygotes exhibit a colorectal tumor phenotype, with median ages at diagnosis of polyposis and CRCs of 36 and 44 years, respectively [43]. Duodenal tumors are the next most frequent lesions in POLE variant heterozygotes, occurring in $9.5 \%$, most frequently duodenal carcinoma, with $15 \%$ of patients developing $\geq 1$ duodenal adenoma. By contrast, endometrial and ovarian cancers are the most common malignancy in female POLD1 variant heterozygotes aged $<50$ years.

\section{Serrated polyposis syndrome}

SPS is characterized by the development of numerous serrated polyps throughout the entire colon, with an increased risk of CRCs [45]. The updated criteria for SPS diagnosis (World Health Organization, 2019) include individuals with $\geq 5$ serrated polyps proximal to the rectum that are $\geq 5 \mathrm{~mm}$ in size, with at least two being $\geq 10 \mathrm{~mm}$ in size, or individuals with $\geq 20$ serrated polyps of any size throughout the colon with $\geq 5$ proximal to the rectum [46]. CRCs arising from the serrated route are characterized by mutations of either KRAS or BRAF, leading to disruption of the WNT signaling pathway and widespread methylation of $\mathrm{CpG}$ islands, respectively. Along with BRAF mutation in both MSI and MSS CRCs, nonsynonymous mutations in RNF43 have been identified in affected siblings of patients with SPS, but not in an unaffected sibling, hence RNF43 mutations are considered causative gene variants [47]. RNF43, an E3 ubiquitin-protein ligase, functions as a negative regulator of WNT signaling by mediating the ubiquitination, endocytosis, and subsequent degradation of the WNT receptor component, Frizzled.

An additional novel disease entity, possibly categorized as SPS, NTHL1 (catalyzing the first step in BER) tumor syndrome, is caused by germline biallelic pathogenic variants in NTHL1, and characterized by an increased lifetime risk for colorectal polyposis, CRC, breast cancer, and variable occurrence of LS- and FAPassociated extracolonic tumors [48]. The cumulative lifetime risk of developing extracolonic cancer by 60 years of age has been estimated to be as much as $35 \%$ to $78 \%$ in patients with NTHL1 tumor syndrome.

\section{Peutz-Jeghers syndrome}

PJS is a hereditary syndrome manifesting in early childhood and characterized by gastrointestinal hamartomatous polyposis, mucocutaneous pigmented macules, and predisposition to various cancers [49]. Patients with PJS are at an increased risk of gastrointestinal cancers including of the colon, small bowel, biliary tract, 
pancreas, stomach, and esophagus, in addition to a wide variety of extraintestinal malignancies, including breast, uterine, cervical, lung, ovarian, and testicular cancers [49]. The overall risks of developing any cancer at ages of $<30,40,50,60$, and 70 years are $1 \%$ to $3 \%, 19 \%, 32 \%, 63 \%$, and $81 \%$, respectively. Among various malignancies, CRC is the most common, with a lifetime risk of $39 \%$, followed by breast cancer in females with a lifetime risk of $32 \%$ to $54 \%$. A pathognomonic feature of intestinal hamartoma is the proliferation of smooth muscle cells derived from the underlying muscularis mucosae, growing in an arborizing pattern to displace the surface epithelium into the submucosa and muscularis propria, and featuring pseudoinvasion [50]. Mucocutaneous presentation includes pigmented dark blue, brown, to black macules distributed on the lips, perioral areas, buccal mucosa, eyes, nostrils, fingertips, palms, soles, and perianal areas, without malignant transformation [49]. The PJS phenotype manifests when germline serine/threonine protein kinase ( $L K B 1)$ mutations are accompanied by an acquired defect/second hit in the other allele in somatic cells, and is transmitted by autosomal dominant inheritance [51]. Loss-of-function mutations of STK11 can be oncogenic because they lead to disruption of the AMPK pathway, aberrant activation of the mammalian target of rapamycin (mTOR) pathway, and increased metabolic glucose and glutamine use via the hypoxia-inducible factor 1- $\alpha$ (HIF-1- $\alpha$ ) pathway. The hamartoma-carcinoma sequence can be explained by 3 potential cellular and molecular pathogenic pathways (including mothers against decapentaplegic homolog 4 [SMAD4] and STK11): dysplastic transformation; altered turnover rate of stem cells, resulting in expanded progenitors; or hamartoma-adenoma transition [52-54].

\section{Juvenile polyposis syndrome}

JPS is an uncommon hamartomatous disorder with significant gastrointestinal malignant potential. JPS can be diagnosed when any of the following clinical criteria are met; more than 5 juvenile polyps in the entire colon, extraintestinal juvenile polyps, or any number of juvenile polyps with family history [55]. JPS is accompanied by hereditary hemorrhagic telangiectasia (HHT), malrotation of the midgut, cardiac and cranial abnormalities, cleft palate, polydactyly, and genitourinary defects [50]. Höfting et al. [56] reviewed 272 JPS cases and described affected sites in order of frequency as the colon (98\%), stomach (14\%), jejunum and ileum (7\%), and duodenum (2\%). JPS polyps are generally relatively large, often exhibit surface erosion, and are unlikely to spread via smooth muscle proliferation. JPS must be distinguished from solitary juvenile polyps, which develop in $2 \%$ of children and adolescents without any malignant transformation [50]. In contrast to PHTS, JPS has significant gastrointestinal malignant potential; however, extraintestinal cancers are uncommon [57]. There is a risk of malignancy from 20 years old, which reaches $68 \%$ by 60 years [50].

JPS is caused by SMAD4 and BMPR1A (ALK3) mutations, with autosomal dominant transmission and incomplete penetrance; reported collective incidence rates are $23 \%$ and $21 \%$ to $38 \%$, respectively $[57,58]$. Mutations of BMPR1A affect BMP receptors lacking a serine-threonine kinase domain that are upstream of SMAD4 in the transforming growth factor- $\beta$ pathway, and result in loss of BMP intracellular signaling through SMAD4 [50]. The landscaper-defect hypothesis was proposed by Kinzler and Vogelstein [59] to explain how stromal overgrowth in JPS predisposes to epithelial malignancy; however, a subsequent cytogenetic study found that epithelial malignancies are likely to develop in JPS through direct progression in epithelial cells, suggesting that SMAD4 acts as a gatekeeper to JPS development [60]. Juvenile polyps should be distinguished from syndrome-specific features of other diseases caused by PTEN mutations; for example, Cronkhite-Canada syndrome is also characterized by gastrointestinal hamartomatous polyposis and was erroneously classified as a hereditary polyposis, but is rather caused by autoimmune inflammation or idiopathic traits [61].

\section{PTEN hamartoma tumor syndrome}

Patients with PHTS, including Bannayan-Riley-Ruvalcaba (BRRS), Cowden (CS), Gorlin (GS), and Proteus-like syndromes, are at increased risk of developing cancer [62]. The reported cumulative lifetime cancer risk (CLTR) for any cancer varies from $81 \%$ to $90 \%$ in patients with PHTS, with a median age at diagnosis of 36 years [62]. The tumor spectrum includes female breast cancer (CLTR, $25 \%-50 \%)$, endometrial cancer $(19 \%-28 \%)$, thyroid cancer $(6 \%-$ $38 \%)$, CRC (9\%-32\%), renal cell cancer $(2 \%-24 \%)$, and melanoma ( $\leq 6 \%)$. There is evidence that some autism spectrum disorders can be classified within PHTS, and these are characterized by CRC, esophageal glycogenic acanthosis, penile macules, testicular lipomatosis, and vascular anomalies [63]. CS features multiple hamartomas, macrocephaly, or Lhermitte-Duclos disease (LDD; accompanied by hamartomatous dysplastic gangliocytoma of the cerebellum), trichilemmomas, and a high risk of benign and malignant neoplasms of the thyroid, breast, uterus, and skin. BRRS features macrocephaly, mental retardation, esophageal glycogenic acanthosis, lipomatosis, hemangiomas, and genital pigmentation, whereas GS presents as multiple nevoid basal cell carcinomas, skeletal abnormalities, odontogenic keratinocytes, macrocephaly, intracranial calcification, and craniofacial abnormalities [64]. Mutations in PTEN (10q23.3) and PTCH (9q31) can rule out almost all patients with JPS, who are exclusively considered in the context of PHTS [57].

PTEN contributes to apoptosis and the cell cycle by affecting the $\mathrm{PI} 3 \mathrm{~K} / \mathrm{AKT} / \mathrm{mTOR}$ pathway. Patients with CS or a CS-like phenotype may also have associated hypermethylation of the KLLN promoter, leading to deregulation of p53-induced apoptosis [65]. Despite initial reports that colonic polyps were found in $40 \%$ of patients with CS, recent data demonstrate that polyps are found in up to $95 \%$ of adults with PTEN mutations [66]. A wide range of polyps have been detected in PHTS, including adenomas, ganglioneuromas, hamartomas, inflammatory polyps, leiomyomas, 
lipomas, and lymphoid polyps [4]. To date, multiple trichilemmomas are most strongly indicative of PTEN mutations and can be seen on the face, including the eyes, mouth, nose, and forehead, as well as the neck, axillae, and hands, along with acral keratosis.

\section{Hereditary mixed polyposis syndrome}

Robust diagnostic criteria for HMPS have yet to be firmly established. HMPS is characterized by few polyps per endoscopy, with a mixture of phenotypes, most commonly adenoma and non-dysplastic mixed serrated/inflammatory polyps. More than $50 \%$ of polyps demonstrate variable amounts of smooth muscle bands interdigitating between the epithelial crypts, a feature common in hamartomatous polyps, but do not contain large bands of arborizing smooth muscle or compartmentalize the colonic crypts, reminiscent of PJS polyps [67]. Gene variants causative of HMPS were previously mapped to the 10q23 chromosomal region, which includes BMPR1A [68]. Among confirmed causative genetic alterations, a $40 \mathrm{~kb}$ duplication including the $3^{\prime}$ end of SCG5 (Ashkenazi Jewish founder mutation) results in aberrant epithelial expression of the mesenchymal BMP antagonist, gremlin1 (GREM1), and is transmitted via autosomal dominant inheritance. Mutations in $K R A S$ or $B R A F, A P C$, or CTNNB1, a CpG island methylator phenotype, and/or p16 loss drive further neoplastic progression [67]. Further, a Korean family with HMPS carrying 2 missense mutations in the APC MCR, affecting codons 1,304 and 1,309, was initially reported as JPS [69]. Epithelial expression of GREM1 may occur in classical serrated adenomas and sporadic premalignant lesions with a hitherto unknown CRC pathogenesis, similar to HMPS polyps [68]. Crypt base stem cells form ectopic crypts and proliferate on accumulation of somatic mutations, enabling initiation of intestinal neoplasia, indicating that these cells may not be the sole cell-of-origin in CRC associated with HMPS polyps.

\section{GENETIC TESTS}

\section{Overview}

Mechanistic knowledge derived from genome-based diagnosis applied using systems biology approaches can accelerate discovery of useful biomarkers and therapeutics [3]. MGPs, comprising a comprehensive cancer panels including HCRC genes, have been developed for this purpose. MGPs can be broadly categorized according to their manufacturers and purposes; for example, institutional or commercial, and syndrome-specific or comprehensive cancer-diagnostic panels. Comprehensive panels have mostly adopted NGS tools designed for efficient identification of pathogenic single or multiple gene variants; however, gene discovery via MGPs generates considerable numbers of variants of unknown significance (VUS) and clinically questionable or nonactionable alterations [70]. Actionable CRC gene variants that have been identified using MGPs include mutations/alterations in APC (the I1307K polymorphism), AXIN2, CHEK2, GREM1, GALANT12, MSH3, MUTYH (monoallelic), NTHL1, POLE, and POLD1 [71].
The reproducibility of established MGP platforms is consistent, with minimal variation in designated mutation subsets, although there are different thresholds for variant calling, particularly of variants with low allele frequency $(\leq 1 \%)[72]$. Herein, new approaches to find rare variants need to consider the 2 criteria described by Bodmer and Bonilla [73], i.e., genes with obviously severe disruption of function with relevant familial trait and abnormal version of phenotype, and unequivocally involved in the biological phenotypes based on biochemical and physiological studies [73].

\section{Multigene panels for novel gene discovery}

According to a genome-wide association study (GWAS) of a Finnish CRC cohort, an association between single-nucleotide polymorphism (SNP) rs992157 at chromosome 2q35 (in the introns of PNKD/TMBIM1) and CRC was independently replicated in a meta-analysis of European ancestry individuals [74]. Another GWAS demonstrated that TRIM4 and PYGL, which encode proteins that influence redox homeostasis and cellular metabolic reprogramming, respectively, are potentially implicated in a novel CRC pathway linked to cell growth and proliferation [75]. Additionally, CXCR1 and CXCR2, which encode cytokine receptors, are currently under clinical investigation as potential therapeutic targets (clinical trial No. NCT02370238). An institution-based comprehensive cancer MGP (OncoPanel; Eurofins Panlabs, Inc. , St. Charles, MO, USA) has a sensitivity of $74 \%$ to $98 \%$ for detection of SNPs, insertions-deletions, copy number variations, and structural variants across 282 genes considered to have roles as pan-cancer drivers [76]. OncoPanel was used to identify receptor tyrosine kinase (RTK) fusions occurring exclusively in KRAS, $N R A S$, and BRAF wild-type CRCs, which play critical roles in $\mathrm{CRC}$ oncogenesis, predicting likely response to epidermal growth factor receptor-directed therapeutics. Although MMR-deficient CRCs with RTK fusions were exclusively detected in tumors with MLH1 promoter hypermethylation, RTK fusions were also identified in MSS CRCs, possibly providing a rare therapeutic target. Another custom-made MGP (HaloPlex; Agilent Technologies, Santa Clara, CA, USA), targeting 112 genes, including established CRC genes and candidate CRC susceptibility genes, identified 17 pathogenic gene variants in 21 samples as potential gene alterations associated with CRC susceptibility, including variants of ATM, AXIN1, AXIN2, BMP4, BRCA1, CCDC18, CHEK2, MUTYH, NUDT7, PICALM, PTPRJ, SLC5A9, TLR2, TWSG1, UBAP2, USP6NL, and ZFP14 [77].

\section{Chip on a bed}

Clinicians can currently choose 4 types of MGP tests to identify the cause of inherited cancer susceptibility: (1) syndrome-specific, (2) cancer-specific high-penetrance MGPs, (3) cancer-specific moderate-penetrance MGPs, and (4) comprehensive cancer, including genes associated with multiple cancers or hereditary cancer syndromes [70]. Genes analyzed using MGPs are categorized 
as high- or moderate-penetrance, based on the expected lifetime cancer risk (graded as $\geq 40 \%,<40 \%$, or unknown) associated with respective cancer predisposition syndromes [31]. Genes associated with LS (MMR genes), adenomatous polyposis (APC and MUTYH), and hamartomatous polyposis (BMPR1A, PTEN, SMAD4, and STK11) syndromes, breast and ovarian cancer (BRCA1/2), familial atypical multiple mole melanoma syndrome (CDKN2A and $C D K 4)$, hereditary diffuse gastric cancer ( $C D H 1)$, and Li-Fraumeni syndrome (TP53) are classified as high penetrance, whereas the remaining 8 genes (ATM, BARD1, BRIP1, CHEK2, NBN, $P A L B 2, R A D 51 C$, and $R A D 51 D)$ are considered moderate-penetrant HCRC.

An assay for SEPT9 DNA methylation has also been assessed for use in CRC screening, shown to have clinical sensitivity of $68 \%$ and adjusted specificity $80 \%$, and is currently approved as an alternative for individuals who refuse colonoscopy [78].

Aberrant methylation of exon-1 sequences within the non-transcribed vimentin gene (VIM) may be a molecular biomarker of CRC, detected in fecal DNA to identify nearly half of individuals with CRC [79]. Multitarget stool-based tests have been developed for noninvasive screening for CRC and its precursors. A multitarget stool DNA test (Cologuard, Exact Sciences, Madison, WI, USA) that combines screening for KRAS mutations and abnormal NDRG4 and BMP3 promoter region methylation was approved by the U.S. Food and Drug Administration, as well as a fecal IHC test for CRC screening [80]. Unlike the SEPT9 DNA methylation test, the National Comprehensive Cancer Network (NCCN) guideline for CRC screening recommends the use of multitarget stool DNA testing as a potential screening modality in averagerisk individuals; however, data determining an appropriate interval for longitudinal screening and how the multitarget stool DNA test should fit within an overall screening program are lacking.

Liquid biopsy stool DNA assays also represent potential tools for early detection of recurrence and monitoring therapeutic response, although important issues have yet to be overcome; for example, epigenetic plasticity in normal non-cancerous cells and epigenomic flexibility $[81,82]$. Another strong argument for MGP testing is that there is considerable overlap among hereditary cancer syndromes and their associated phenotypes [70]. Moreover, evidence supporting clinical recommendations based on mutations in moderate-penetrance genes is lacking. Although rigorous cost-effectiveness analyses are beyond the scope of this review, MGP testing offers a lower cost per gene by facilitating parallel, rather than sequential, gene analysis, thereby reducing ancillary costs, including specialist consultations [70].

\section{SURVEILLANCE APPROACHES}

\section{Overview}

Many recently described HCRC surveillance schemes appear to be either too complex or too stringent for application in clinical practice. In this section, we primarily focus on recently revised and notable HCRC surveillance approaches, based on competent validation or likely impact (Table 3). Major determining factors for HCRC surveillance include cancer risk, age at diagnosis, family history, and phenotypic expression. Current strategies are mainly based on guidelines from the American College of Gastroenterology, Gastroenterology/Association of Coloproctology of Great Britain and Ireland (BSG/ACPGBI, 2020), the NCCN (ver. 1-2021), and the American Society of Colon and Rectal Surgeons [83-86]. Generally, mutation carriers and individuals at risk of well-known HCRCs, particularly those with a family history, require intensive surveillance and prophylactic surgery if necessary, as well as family counseling and management tailored according to the particular syndrome.

\section{Surveillance approaches for Lynch syndrome and associated spectra}

Screening for CRC by colonoscopy should be performed at least biennially, beginning at age of 20 to 25 years in individuals at risk based on the Amsterdam criteria II, or affected with LS. Colectomy with ileorectal anastomosis (IRA) is the preferred treatment for patients with LS who develop CRC, while less extensive surgery may be considered in patients aged $>60$ to 65 years. A decision regarding whether segmental or total/near total colectomy is preferred should balance the risks of metachronous cancer, the functional consequences, and patient age and/or wishes. Parry et al. [87] reported that the risk of metachronous CRC is reduced by $31 \%$ for every $10 \mathrm{~cm}$ of large bowel excision. Annual colonoscopy should be considered in confirmed MMR mutation carriers, along with annual screening for endometrial and ovarian cancer in females by Pap-smear/endometrial biopsy and transvaginal ultrasound, starting at age of 30 to 35 years. Risk management for gastric, small bowel, or pancreatic surveillance in patients with LS is generally recommended within the scope of a clinical trial. Cancer risk in extracolonic viscera may be increased in carriers of pathogenic variants in $M L H 1$ and $M S H 2$. Screening for gastric and duodenal cancer by baseline esophagogastroduodenoscopy (EGD) at age of 30 to 35 years may be considered in at-risk patients with LS or in endemic countries, with treatment of Helicobacter pylori when detected. Patients with LS can be advised to take aspirin daily to reduce CRC risk, regardless of surgical intervention. The benefits of regular aspirin intake take at least 3 to 5 years to become evident; however, taking aspirin for $<2$ years does not appear to confer any benefit in reducing risk or increasing survival. LS-associated spectra can be managed in accordance with the principles set out for LS, or based on the patient's phenotypic traits. In particular, in patients with eligible MMR-deficient CRCs between the ages of 30 and 50 years at diagnosis of CRC, MGP testing may be applicable on the basis of FCCTX, or other clinical parameters that alter the threshold for genetic testing, while a balance between clinical requirements and ethical considerations must be ensured. 
Table 3. Surveillance recommendations for hereditary colorectal cancer syndrome

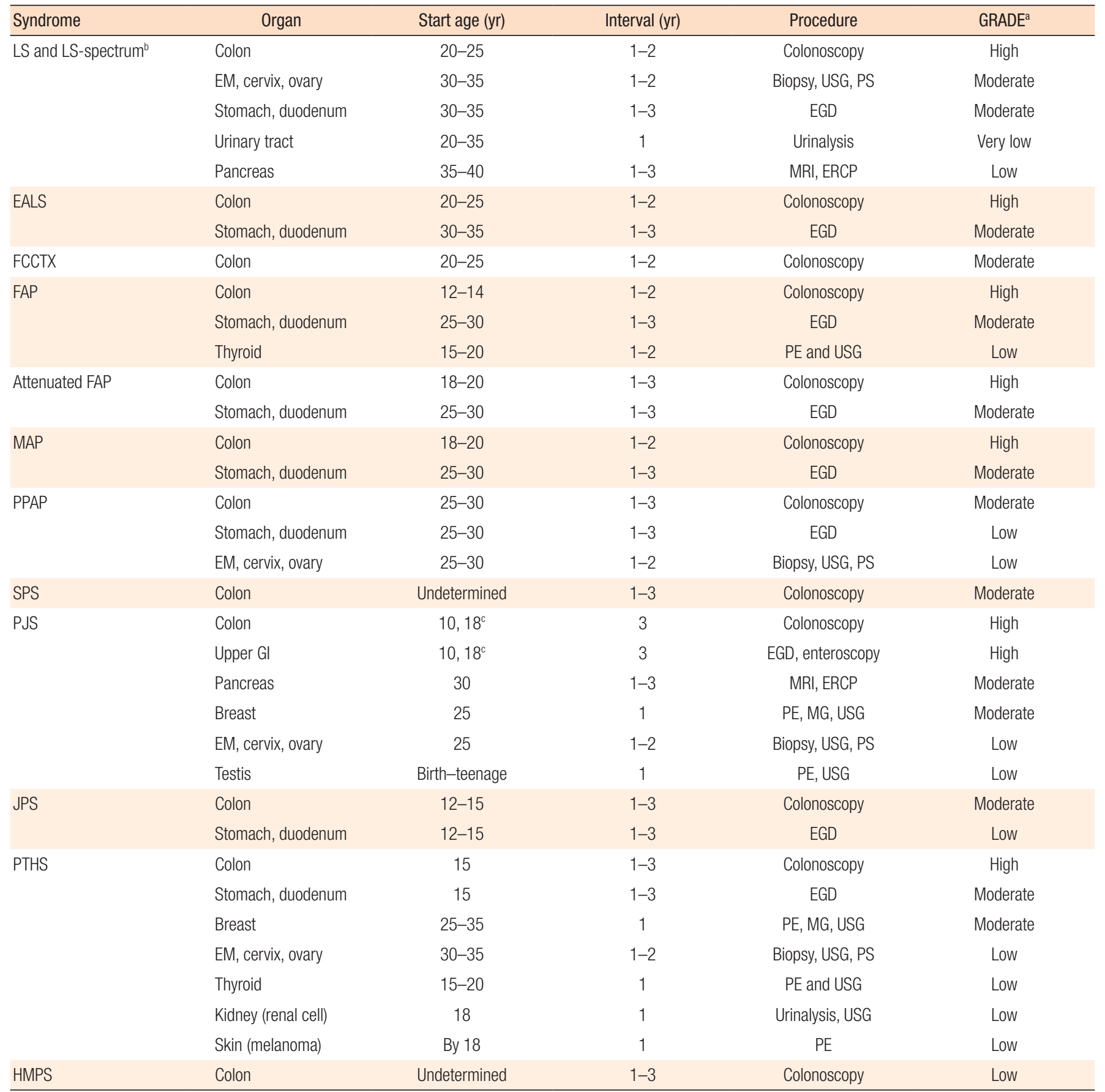

LS, Lynch syndrome; EM, endometrium; USG, ultrasonography; PS, Pap smear; EGD, esophagoduodenoscopy; MRI, magnetic resonance imaging; ERCP, endoscopic retrograde cholangiopancreatography; EALS, EPCAM-associated LS; FCCTX, familial colorectal cancer type X; FAP, familial adenomatous polyposis; PE, physical examination; MAP, MUTYH-associated polyposis; PPAP, polymerase-proofreading-associated polyposis; SPS, sessile polyposis syndrome; PJS, Peutz-Jeghers syndrome; Gl, gastrointestinal; MG, mammography; JPS, juvenile polyposis syndrome; PTHS, PTEN hamartoma syndrome; HMPS, hereditary mixed polyposis syndrome.

aGRADE (Grading of Recommendations Assessment, Development and Evaluation) system was used to grade the strength of recommendations and the quality of evidence. 'bS-spectrum includes Muir-Torre syndrome, Turcot syndrome, and constitutional mismatch repair deficiency. 'At age of 8 years, if present every 3 years; if no polyps, repeat at age of 18 years, then every 3 years or earlier on symptom. 


\section{Surveillance approaches in patients with inherited polyposis syndrome}

General colon screening for children at risk for classical FAP starts at age of 12 to 14 years with follow-up sigmoidoscopy every 1 to 2 years, while those initially diagnosed at an older age should undergo colonoscopy at first examination. Individuals with bilateral and multiple CHRPE should be referred for FAP screening, including genetic testing of APC variants and colonoscopy. Total proctocolectomy with ileal-pouch-anal anastomosis (IPAA) must be offered to patients with FAP, particularly those with rectal cancer, a large and significant rectal polyp burden ( $>20$ synchronous adenomas, high-grade dysplasia, and $>30-\mathrm{mm}$ adenomas), and a profuse polyp phenotype. Pouch polyposis can generally be treated by polypectomy or chemoprevention with sulindac, which leads to considerable regression and prevention of colorectal adenomas but has uncertain value for cancer prevention. Screening for gastric and proximal small bowel tumors should be conducted by EGD, starting at age of 25 to 30 years. Gastric polyps occur in $23 \%$ to $100 \%$ of patients with FAP, mostly presenting as fundic gland polyps and rarely progressing to cancer. FAP is accompanied by duodenal adenoma in $>50 \%$ of patients and duodenal adenocarcinoma in up to $12 \%$ of patients. Duodenal surveillance by EGD should be repeated according to Spigelman staging, as follows; every 5 years for stage $0-I$, every 3 years for stage II, annually for stage III, and every $0.5-1$ year for stage IV [88]. For desmoid tumors, surgical resection is not generally recommended and is strictly reserved for small and well-defined tumors with clear margins. First-line treatment includes high-dose selective estrogen receptor modulators and sulindac, and leads to regression in $85 \%$ of patients with stable desmoid size, while chemotherapy or radiotherapy can be considered for patients with intractable disease.

Colorectal screening should commence at age of 18 to 20 years in patients with MAP and biallelic MUTYH variants; however, in monoallelic MUTYH pathogenic variant carriers, the risk of CRC is not sufficiently different from the population risk, hence routine colonoscopy is not recommended. Timing and type of surgery in patients with biallelic MUTYH mutations depend on the ability to maintain clearance of polyps, and otherwise follows the principles for FAP. The observed frequency of duodenal adenomas is much lower than that observed in FAP but greater than that in the general population, hence EGD is recommended from age of 25 to 30 years. AFAP is inherited in an autosomal dominant manner, exclusive of MAP. The emergence of adenomas and cancer is usually delayed by 10 to 20 years compared with typical FAP. In a large study of 276 patients with MAP, 17\% had extracolonic lesions, with an estimated $38 \%$ lifetime risk of extracolonic malignancy, which is approximately double the risk in the general population. Surgical treatment conforms to that used for MAP and is reserved for patients without colonoscopic clearance or associated CRC. Annual thyroid screening by ultrasound may be recommended, but is not obligatory, for individuals affected with FAP,
MAP, and AFAP.

As SPS does not yet have a clear genetic etiology, genetic testing is not routinely recommended. A strong association between smoking and SPS has been reported, with $60 \%$ current or past smokers [89]. Patients with serrated polyposis require colonoscopy every 1 to 3 years, with removal of all polyps of $>5 \mathrm{~mm}$. The majority of index individuals exhibit a pancolonic polyp distribution (89\%-96\%) and presence of adenomas (78\%-80\%), with mean age at diagnosis of CRC 48 years. Surgery is advised when polyps cannot be controlled by endoscopy and subtotal colectomy with IRA is a reasonable option, given the risks of metachronous CRC.

Once a disease-causing mutation is identified in a patient with PJS, other family members should undergo STK11 mutation-specific testing to determine appropriate surveillance. The risk of malignancy in PJS includes colorectal, breast, pancreatic, gynecological, small bowel, lung, and gastroesophageal cancers, in that order. Patients with PJS develop gastrointestinal polyposis as early as 10 years old, with the small intestine the most common site; hence, it is imperative to evaluate the small intestine by enteroscopy, in addition to colonoscopy, beginning in early adolescence. More recent data reveal that gastrointestinal cancers are less of a clinical problem than pancreatic and breast cancers, which are the most commonly diagnosed malignancies in PJS. Endoscopic clearance of all polyps is preferable, but not always possible; therefore, colectomy is often required to control colonic polyps and neoplastic changes, as well as the accompanying intussusception that occurs in $69 \%$ of patients. PJS polyps overexpress COX-2, suggesting that COX-2 inhibitors may be useful in reducing polyps, and everolimus (an mTOR inhibitor) is under clinical investigation.

JPS most frequently presents as hamartomatous polyps in the colon. The average age at diagnosis is 18 years but can be older, and rectal bleeding with anemia is the most common presenting symptom. Cardiovascular examination and evaluation for HHT should be considered for SMAD4 mutation carriers. Patients with a SMAD4 pathogenic variant should be evaluated for HHT and appropriately managed in conjunction with a specialist center. Colonoscopy, preferably with EGD and enteroscopy, is recommended beginning at age of 12 to 15 years, or earlier if symptoms occur, and should be repeated every 1 to 3 years. Total colectomy with IRA or proctocolectomy and IPAA is indicated for endoscopically unmanageable or malignant lesions.

PHTS can be diagnosed by the presence of 3 or more major criteria, 1 of which must include macrocephaly, LDD, or gastrointestinal hamartomas, otherwise 2 major and 3 minor criteria are required [63]. Patients with PHTS are prone to exhibit a severe form of juvenile polyposis, with onset in early childhood and increased risk of extraintestinal manifestations, including breast, follicular thyroid, and endometrial cancers. Individuals with multiple gastrointestinal hamartomas or ganglioneuromas should also be evaluated for CS and related conditions. The esophagus frequently develops diffuse glycogenic acanthosis, which is observed in $\geq 80 \%$ of individuals with PHTS. Surveillance of affected or at-risk pa- 
tients should include colon screening every 1 to 3 years, starting from age of 15 years, with advised consideration of extracolonic malignancies, including stomach, small bowel, thyroid, breast, uterus, kidney, and skin (melanoma).

HMPS was originally described in a large Ashkenazi Jewish family with multiple colorectal polyps and cancer. Affected patients exhibit mixed juvenile-adenomatous polyps, serrated adenomas, and even inflammatory polyps and adenocarcinomas, with a mean age of polyp detection of 28 years. Annual or biennial colonoscopy is recommended and surgery is reserved for unmanageable polyp burden.

\section{CONCLUSIONS}

HCRC enlightens principal routes of colorectal carcinogenesis, although the hereditary nature of a subset of serrated, hamartomatous, and mixed polyposis remains uncertain. Unidentified HCRC requires exploration, even through a straight gate, given that established routes in LS and FAP, identified MSI and chromosome instability, respectively, as drivers of carcinogenesis. The field of gene panel testing for inherited cancer risk assessment is rapidly evolving and has significant potential to provide valuable information. NGS-based MGPs should enable definition of HCRC where the causative gene is unknown; for example, by identification of FCCTX. At present, rare genes or VUS generally exhibit low penetrance and await further validation of related familial traits, as well as biochemical and physiological implications. Such variants are otherwise overlooked in family-based studies, due to incomplete co-segregation, similar to findings from various GWAS trials even with large sample sizes reaching statistical significance. As hereditary syndromes are mainly attributable to genomic constitutions, that is, distinctive ancestral traits segregating in populations of a specific ethnicity, an integrative national HCRC registry and guideline are urgently required, and the idea that it is now "too late" for such an approach should be resisted.

\section{CONFLICT OF INTEREST}

No potential conflict of interest relevant to this article was reported.

\section{ACKNOWLEDGMENTS}

The authors sincerely appreciate the Cancer and Immunogenetics Laboratory, University of Oxford, UK for the expertise cooperation with the Laboratory of Cancer Biology and Genetics, Asan Institute for Life Sciences, Seoul, Korea, particularly in the study of inherited polyposis syndrome. We appreciate all members of the Korean Society of Coloproctology for their sincere affection and dedication to treating hereditary colorectal cancer.

\section{REFERENCES}

1. Vignot S, Lefebvre C, Frampton GM, Meurice G, Yelensky R, Palmer $\mathrm{G}$, et al. Comparative analysis of primary tumour and matched metastases in colorectal cancer patients: evaluation of concordance between genomic and transcriptional profiles. Eur J Cancer 2015; 51:791-9.

2. Sottoriva A, Kang H, Ma Z, Graham TA, Salomon MP, Zhao J, et al. A Big Bang model of human colorectal tumor growth. Nat Genet 2015;47:209-16.

3. Dienstmann R, Vermeulen L, Guinney J, Kopetz S, Tejpar S, Tabernero J. Consensus molecular subtypes and the evolution of precision medicine in colorectal cancer. Nat Rev Cancer 2017;17:79-92.

4. Bodmer WF, Bailey CJ, Bodmer J, Bussey HJ, Ellis A, Gorman P, et al. Localization of the gene for familial adenomatous polyposis on chromosome 5. Nature 1987;328:614-6.

5. Fearon ER, Vogelstein B. A genetic model for colorectal tumorigenesis. Cell 1990;61:759-67.

6. Kwak HD, Ju JK. Immunological differences between right-sided and left-sided colorectal cancers: a comparison of embryologic midgut and hindgut. Ann Coloproctol 2019;35:342-6.

7. Wells K, Wise PE. Hereditary colorectal cancer syndromes. Surg Clin North Am 2017;97:605-25.

8. Nam S, Choi YJ, Kim DW, Park EC, Kang JG. Risk factors for colorectal cancer in Korea: a population-based retrospective cohort study. Ann Coloproctol 2019;35:347-56.

9. Crouch D, Bodmer WF. Polygenic inheritance, GWAS, polygenic risk scores, and the search for functional variants. Proc Natl Acad Sci U S A 2020;117:18924-33.

10. Stoffel EM, Boland CR. Genetics and genetic testing in hereditary colorectal cancer. Gastroenterology 2015;149:1191-203.

11. Burt RW, Leppert MF, Slattery ML, Samowitz WS, Spirio LN, Kerber RA, et al. Genetic testing and phenotype in a large kindred with attenuated familial adenomatous polyposis. Gastroenterology 2004;127:444-51.

12. Peltomäki P, Olkinuora A, Nieminen TT. Updates in the field of hereditary nonpolyposis colorectal cancer. Expert Rev Gastroenterol Hepatol 2020;14:707-20.

13. Senter L, Clendenning M, Sotamaa K, Hampel H, Green J, Potter JD, et al. The clinical phenotype of Lynch syndrome due to germline PMS2 mutations. Gastroenterology 2008;135:419-28.

14. Baglietto L, Lindor NM, Dowty JG, White DM, Wagner A, Gomez Garcia EB, et al. Risks of Lynch syndrome cancers for MSH6 mutation carriers. J Natl Cancer Inst 2010;102:193-201.

15. Edelstein DL, Axilbund J, Baxter M, Hylind LM, Romans K, Griffin CA, et al. Rapid development of colorectal neoplasia in patients with Lynch syndrome. Clin Gastroenterol Hepatol 2011;9: 340-3.

16. Järvinen HJ, Renkonen-Sinisalo L, Aktán-Collán K, Peltomäki P, Aaltonen LA, Mecklin JP. Ten years after mutation testing for Lynch syndrome: cancer incidence and outcome in mutation-positive and mutation-negative family members. J Clin Oncol 2009;27: 
4793-7.

17. John AM, Schwartz RA. Muir-Torre syndrome (MTS): an update and approach to diagnosis and management. J Am Acad Dermatol 2016;74:558-66.

18. Guillén-Ponce C, Castillejo A, Barberá VM, Pascual-Ramírez JC, Andrada E, Castillejo MI, et al. Biallelic MYH germline mutations as cause of Muir-Torre syndrome. Fam Cancer 2010;9:151-4.

19. Gadish T, Tulchinsky H, Deutsch AA, Rabau M. Pinealoblastoma in a patient with familial adenomatous polyposis: variant of Turcot syndrome type 2 ? Report of a case and review of the literature. Dis Colon Rectum 2005;48:2343-6.

20. Hamilton SR, Liu B, Parsons RE, Papadopoulos N, Jen J, Powell $\mathrm{SM}$, et al. The molecular basis of Turcot's syndrome. N Engl J Med 1995;332:839-47.

21. Paraf F, Jothy S, Van Meir EG. Brain tumor-polyposis syndrome: two genetic diseases? J Clin Oncol 1997;15:2744-58.

22. Shuen AY, Lanni S, Panigrahi GB, Edwards M, Yu L, Campbell $\mathrm{BB}$, et al. Functional repair assay for the diagnosis of constitutional mismatch repair deficiency from non-neoplastic tissue. J Clin Oncol 2019;37:461-70.

23. Bakry D, Aronson M, Durno C, Rimawi H, Farah R, Alharbi QK, et al. Genetic and clinical determinants of constitutional mismatch repair deficiency syndrome: report from the constitutional mismatch repair deficiency consortium. Eur J Cancer 2014;50:987-96.

24. van der Klift HM, Mensenkamp AR, Drost M, Bik EC, Vos YJ, Gille $\mathrm{HJ}$, et al. Comprehensive mutation analysis of PMS2 in a large cohort of probands suspected of lynch syndrome or constitutional mismatch repair deficiency syndrome. Hum Mutat 2016;37:116279.

25. Ligtenberg MJ, Kuiper RP, Chan TL, Goossens M, Hebeda KM, Voorendt $\mathrm{M}$, et al. Heritable somatic methylation and inactivation of MSH2 in families with Lynch syndrome due to deletion of the 3' exons of TACSTD1. Nat Genet 2009;41:112-7.

26. Pathak SJ, Mueller JL, Okamoto K, Das B, Hertecant J, Greenhalgh $\mathrm{L}$, et al. EPCAM mutation update: variants associated with congenital tufting enteropathy and Lynch syndrome. Hum Mutat 2019;40:142-61.

27. Tutlewska K, Lubinski J, Kurzawski G. Germline deletions in the EPCAM gene as a cause of Lynch syndrome: literature review. Hered Cancer Clin Pract 2013;11:9.

28. Kempers MJ, Kuiper RP, Ockeloen CW, Chappuis PO, Hutter P, Rahner N, et al. Risk of colorectal and endometrial cancers in EPCAM deletion-positive Lynch syndrome: a cohort study. Lancet Oncol 2011;12:49-55.

29. Nejadtaghi M, Jafari H, Farrokhi E, Samani KG. Familial colorectal cancer type X (FCCTX) and the correlation with various genes: a systematic review. Curr Probl Cancer 2017;41:388-97.

30. Therkildsen C, Rasmussen M, Smith-Hansen L, Kallemose T, Lindberg LJ, Nilbert M. Broadening risk profile in familial colorectal cancer type $\mathrm{X}$ : increased risk for five cancer types in the national Danish cohort. BMC Cancer 2020;20:345.

31. Yurgelun MB, Allen B, Kaldate RR, Bowles KR, Judkins T, Kaushik
$\mathrm{P}$, et al. Identification of a variety of mutations in cancer predisposition genes in patients with suspected Lynch syndrome. Gastroenterology 2015;149:604-13.

32. Sereno M, Merino M, López-Gómez M, Gómez-Raposo C, Zambrana Tébar F, Moreno Rubio J, et al. MYH polyposis syndrome: clinical findings, genetics issues and management. Clin Transl Oncol 2014;16:675-9.

33. Petersen GM, Slack J, Nakamura Y. Screening guidelines and premorbid diagnosis of familial adenomatous polyposis using linkage. Gastroenterology 1991;100:1658-64.

34. Jasperson KW, Tuohy TM, Neklason DW, Burt RW. Hereditary and familial colon cancer. Gastroenterology 2010;138:2044-58.

35. Goodenberger M, Lindor NM. Lynch syndrome and MYH-associated polyposis: review and testing strategy. J Clin Gastroenterol 2011;45:488-500.

36. Grover S, Kastrinos F, Steyerberg EW, Cook EF, Dewanwala A, Burbidge LA, et al. Prevalence and phenotypes of APC and MUTYH mutations in patients with multiple colorectal adenomas. JAMA 2012;308:485-92.

37. Fearnhead NS, Britton MP, Bodmer WF. The ABC of APC. Hum Mol Genet 2001;10:721-33.

38. Groves C, Lamlum H, Crabtree M, Williamson J, Taylor C, Bass S, et al. Mutation cluster region, association between germline and somatic mutations and genotype-phenotype correlation in upper gastrointestinal familial adenomatous polyposis. Am J Pathol 2002;160:2055-61.

39. Rohlin A, Engwall Y, Fritzell K, Göransson K, Bergsten A, Einbeigi Z, et al. Inactivation of promoter $1 \mathrm{~B}$ of APC causes partial gene silencing: evidence for a significant role of the promoter in regulation and causative of familial adenomatous polyposis. Oncogene 2011;30:4977-89.

40. Nielsen M, Morreau H, Vasen HF, Hes FJ. MUTYH-associated polyposis (MAP). Crit Rev Oncol Hematol 2011;79:1-16.

41. Kim JC, Ka IH, Lee YM, Koo KH, Kim HC, Yu CS, et al. MYH, OGG1, MTH1, and APC alterations involved in the colorectal tumorigenesis of Korean patients with multiple adenomas. Virchows Arch 2007;450:311-9.

42. Adam R, Spier I, Zhao B, Kloth M, Marquez J, Hinrichsen I, et al. Exome sequencing identifies biallelic MSH3 germline mutations as a recessive subtype of colorectal adenomatous polyposis. Am J Hum Genet 2016;99:337-51.

43. Palles C, Martin L, Domingo E, Chegwidden L, McGuire J, Cuthill $\mathrm{V}$, et al. The clinical features of polymerase proof-reading associated polyposis (PPAP) and recommendations for patient management. Fam Cancer 2021 May 5 [Epub]. https://doi.org/10.1007/ s10689-021-00256-y.

44. Mur P, García-Mulero S, Del Valle J, Magraner-Pardo L, Vidal A, Pineda M, et al. Role of POLE and POLD1 in familial cancer. Genet Med 2020;22:2089-100.

45. Stanich PP, Pearlman R. Hereditary or not? Understanding serrated polyposis syndrome. Curr Treat Options Gastroenterol 2019;17: 692-701. 
46. Muller C, Yamada A, Ikegami S, Haider H, Komaki Y, Komaki F, et al. Risk of colorectal cancer in serrated polyposis syndrome: a systematic review and metaanalysis. Clin Gastroenterol Hepatol 2021 Jun 2 [Epub]. https://doi.org/10.1016/j.cgh.2021.05.057.

47. Yan H, Lai J, Ho SL, Leung WK, Law WL, Lee J, et al. RNF43 germline and somatic mutation in serrated neoplasia pathway and its association with BRAF mutation. Gut 2017;66:1645-56.

48. Grolleman JE, de Voer RM, Elsayed FA, Nielsen M, Weren R, Palles $\mathrm{C}$, et al. Mutational signature analysis reveals NTHL1 deficiency to cause a multi-tumor phenotype. Cancer Cell 2019;35:256-66.

49. Tacheci I, Kopacova M, Bures J. Peutz-Jeghers syndrome. Curr Opin Gastroenterol 2021;37:245-54.

50. Chow E, Macrae F. A review of juvenile polyposis syndrome. J Gastroenterol Hepatol 2005;20:1634-40.

51. Daniell J, Plazzer JP, Perera A, Macrae F. An exploration of genotype-phenotype link between Peutz-Jeghers syndrome and STK11: a review. Fam Cancer 2018;17:421-7.

52. Bosman FT. The hamartoma-adenoma-carcinoma sequence. J Pathol 1999;188:1-2.

53. Korsse SE, Biermann K, Offerhaus GJ, Wagner A, Dekker E, Mathus-Vliegen EM, et al. Identification of molecular alterations in gastrointestinal carcinomas and dysplastic hamartomas in PeutzJeghers syndrome. Carcinogenesis 2013;34:1611-9.

54. Jansen M, Ten Klooster JP, Offerhaus GJ, Clevers H. LKB1 and AMPK family signaling: the intimate link between cell polarity and energy metabolism. Physiol Rev 2009;89:777-98.

55. Jass JR, Williams CB, Bussey HJ, Morson BC. Juvenile polyposis: a precancerous condition. Histopathology 1988;13:619-30.

56. Höfting I, Pott G, Stolte M. The syndrome of juvenile polyposis. Leber Magen Darm 1993;23:107-8, 111-2.

57. Woodford-Richens K, Bevan S, Churchman M, Dowling B, Jones D, Norbury CG, et al. Analysis of genetic and phenotypic heterogeneity in juvenile polyposis. Gut 2000;46:656-60.

58. Zhou XP, Woodford-Richens K, Lehtonen R, Kurose K, Aldred M, Hampel $\mathrm{H}$, et al. Germline mutations in BMPR1A/ALK3 cause a subset of cases of juvenile polyposis syndrome and of Cowden and Bannayan-Riley-Ruvalcaba syndromes. Am J Hum Genet 2001; 69:704-11.

59. Kinzler KW, Vogelstein B. Landscaping the cancer terrain. Science 1998;280:1036-7.

60. Woodford-Richens K, Williamson J, Bevan S, Young J, Leggett B, Frayling I, et al. Allelic loss at SMAD4 in polyps from juvenile polyposis patients and use of fluorescence in situ hybridization to demonstrate clonal origin of the epithelium. Cancer Res 2000;60: 2477-82.

61. Sweetser S, Ahlquist DA, Osborn NK, Sanderson SO, Smyrk TC, Chari ST, et al. Clinicopathologic features and treatment outcomes in Cronkhite-Canada syndrome: support for autoimmunity. Dig Dis Sci 2012;57:496-502.

62. Hendricks LA, Hoogerbrugge N, Schuurs-Hoeijmakers JH, Vos JR. A review on age-related cancer risks in PTEN hamartoma tumor syndrome. Clin Genet 2021;99:219-25.
63. Pilarski R, Burt R, Kohlman W, Pho L, Shannon KM, Swisher E. Cowden syndrome and the PTEN hamartoma tumor syndrome: systematic review and revised diagnostic criteria. J Natl Cancer Inst 2013;105:1607-16.

64. Borowsky J, Setia N, Rosty C, Conrad R, Susman R, Misdraji J, et al. Spectrum of gastrointestinal tract pathology in a multicenter cohort of 43 Cowden syndrome patients. Mod Pathol 2019;32: 1814-22.

65. Bennett KL, Mester J, Eng C. Germline epigenetic regulation of KILLIN in Cowden and Cowden-like syndrome. JAMA 2010; 304:2724-31.

66. Pilarski R. PTEN hamartoma tumor syndrome: a clinical overview. Cancers (Basel) 2019;11:844.

67. Plesec T, Brown K, Allen C, A Burke C, Church J, Kalady M, et al. Clinicopathological features of a kindred with SCG5-GREM1-associated hereditary mixed polyposis syndrome. Hum Pathol 2017; 60:75-81.

68. Davis H, Irshad S, Bansal M, Rafferty H, Boitsova T, Bardella C, et al. Aberrant epithelial GREM1 expression initiates colonic tumorigenesis from cells outside the stem cell niche. Nat Med 2015; 21:62-70.

69. Kim JC, Roh SA, Yu CS, Lee HI, Gong G. Familial juvenile polyposis coli with APC gene mutation. Am J Gastroenterol 1997;92: 1913-5.

70. Hall MJ, Forman AD, Pilarski R, Wiesner G, Giri VN. Gene panel testing for inherited cancer risk. J Natl Compr Canc Netw 2014; 12:1339-46.

71. Gupta S, Provenzale D, Llor X, Halverson AL, Grady W, Chung DC, et al. NCCN Guidelines insights: genetic/familial high-risk assessment. Colorectal, version 2.2019. J Natl Compr Canc Netw 2019;17:1032-41.

72. Malapelle U, Mayo-de-Las-Casas C, Molina-Vila MA, Rosell R, Savic S, Bihl M, et al. Consistency and reproducibility of nextgeneration sequencing and other multigene mutational assays: a worldwide ring trial study on quantitative cytological molecular reference specimens. Cancer Cytopathol 2017;125:615-26.

73. Bodmer W, Bonilla C. Common and rare variants in multifactorial susceptibility to common diseases. Nat Genet 2008;40:695-701.

74. Tanskanen T, van den Berg L, Välimäki N, Aavikko M, Ness-Jensen E, Hveem K, et al. Genome-wide association study and metaanalysis in Northern European populations replicate multiple colorectal cancer risk loci. Int J Cancer 2018;142:540-6.

75. Bien SA, Su YR, Conti DV, Harrison TA, Qu C, Guo X, et al. Genetic variant predictors of gene expression provide new insight into risk of colorectal cancer. Hum Genet 2019;138:307-26.

76. Singh H, Li YY, Spurr LF, Shinagare AB, Abhyankar R, Reilly E, et al. Molecular characterization and therapeutic targeting of colorectal cancers harboring receptor tyrosine kinase fusions. Clin Cancer Res 2021;27:1695-705.

77. Hansen MF, Johansen J, Sylvander AE, Bjørnevoll I, Talseth-Palmer BA, Lavik L, et al. Use of multigene-panel identifies pathogenic variants in several CRC-predisposing genes in patients previously 
tested for Lynch Syndrome. Clin Genet 2017;92:405-14.

78. Church TR, Wandell M, Lofton-Day C, Mongin SJ, Burger M, Payne SR, et al. Prospective evaluation of methylated SEPT9 in plasma for detection of asymptomatic colorectal cancer. Gut 2014; 63:317-25.

79. Chen WD, Han ZJ, Skoletsky J, Olson J, Sah J, Myeroff L, et al. Detection in fecal DNA of colon cancer-specific methylation of the nonexpressed vimentin gene. J Natl Cancer Inst 2005;97: 1124-32.

80. Imperiale TF, Ransohoff DF, Itzkowitz SH, Levin TR, Lavin P, Lidgard GP, et al. Multitarget stool DNA testing for colorectalcancer screening. N Engl J Med 2014;370:1287-97.

81. Leal A, Sidransky D, Brait M. Tissue and cell-free DNA-based epigenomic approaches for cancer detection. Clin Chem 2020;66: 105-16.

82. Che Alhadi S, Wan Zain WZ, Zahari Z, Md Hashim MN, Syed Abd Aziz SH, Zakaria Z, et al. The use of M2-pyruvate kinase as a stool biomarker for detection of colorectal cancer in tertiary teaching hospital: a comparative study. Ann Coloproctol 2020;36:409-14.

83. Syngal S, Brand RE, Church JM, Giardiello FM, Hampel HL, Burt RW, et al. ACG clinical guideline: genetic testing and management of hereditary gastrointestinal cancer syndromes. Am J Gastroenterol 2015;110:223-62.
84. Monahan KJ, Bradshaw N, Dolwani S, Desouza B, Dunlop MG, East JE, et al. Guidelines for the management of hereditary colorectal cancer from the British Society of Gastroenterology (BSG)/Association of Coloproctology of Great Britain and Ireland (ACPGBI)/United Kingdom Cancer Genetics Group (UKCGG). Gut 2020;69:411-44.

85. Herzig DO, Buie WD, Weiser MR, You YN, Rafferty JF, Feingold $\mathrm{D}$, et al. Clinical practice guidelines for the surgical treatment of patients with Lynch syndrome. Dis Colon Rectum 2017;60:137-43.

86. Herzig D, Hardiman K, Weiser M, You N, Paquette I, Feingold DL, et al. The American Society of Colon and Rectal Surgeons clinical practice guidelines for the management of inherited polyposis syndromes. Dis Colon Rectum 2017;60:881-94.

87. Parry S, Win AK, Parry B, Macrae FA, Gurrin LC, Church JM, et al. Metachronous colorectal cancer risk for mismatch repair gene mutation carriers: the advantage of more extensive colon surgery. Gut 2011;60:950-7.

88. Spigelman AD, Williams CB, Talbot IC, Domizio P, Phillips RK. Upper gastrointestinal cancer in patients with familial adenomatous polyposis. Lancet 1989;2:783-5.

89. Cauley CE, Hassab TH, Feinberg A, Church J. Sessile serrated polyposis: not an inherited syndrome? Dis Colon Rectum 2020; 63:183-9. 